\title{
A NOÇÃO DE EQUIVALÊNCIA DE KOLLER: UNIVERSALISMO RELATIVIZADO?
}

\author{
Carolina Ribeiro Minchin 1 \\ -Universidade de São Paulo, São Paulo, São Paulo, Brasil
}

\begin{abstract}
Resumo: Neste artigo será discutido o conceito de equivalência tradutória proposto por Werner Koller na $7^{\mathrm{a}}$ edição de seu livro, Einführung in die Übersetzungswissenschaft (2004). As considerações serão feitas à luz da comparação entre a concepção de linguagem e a concepção de tradução defendidas pelo autor na obra citada. Partindo do princípio de que a concepção de linguagem adotada por um estudioso da tradução influencia a sua visão de tradução, como defendido por Kopetzki (1996), nosso objetivo é demonstrar que Koller adota uma concepção relativista de linguagem e que sua concepção de tradução e sua noção de equivalência, em alguns aspectos, vão de encontro ao caráter universalista geralmente atribuído a este conceito no âmbito dos Estudos de Tradução.
\end{abstract}

Palavras-chave: Equivalência; Koller; Tradução; Relativismo; Universalismo.

\section{KOLLER'S CONCEPT OF EQUIVALENCE: RELATIVISED UNIVERSALISM?}

\begin{abstract}
This article discusses the concept of translation equivalence as suggested by Werner Koller in the 7th edition of his book, Einführung in die Übersetzungswissenschaft (2004). The analysis is based on a comparison of the author's views on language and translation. Assuming, as proposed by Kopetzki (1996), that a translation scholar's perspective on language has a decisive influence on his or her view about translation, the main objective of this paper is to demonstrate that Koller favours a relativistic understanding of language and that, in some respects, his take on translation and translation equivalence challenge the universalistic character that is usually attributed to this concept in Translation Studies. Keywords: Equivalence; Koller; Translation; Relativism; Universalism.
\end{abstract}




\section{Equivalência em tradução}

$\mathrm{Na}$ introdução a seu livro Tradução e diferença, Rodrigues (2000) elenca as diversas formas que o conceito da equivalência assumiu ao longo dos Estudos da Tradução. Segundo a autora, dicotomias do tipo tradução "literal" ou "livre" e "fiel" ou "criativa" remontam à Roma antiga, a autores como Cícero e Horácio e, no século XX, ganharam uma roupagem mais científica, com nomes como "equivalência formal" e "equivalência dinâmica", segundo a tipologia de Nida (1964) (cf. RODRIGUES, 2000, p. 21).

Ainda de acordo com Rodrigues:

Mesmo que não se determine quando nem por quem o conceito [de equivalência] foi introduzido nos estudos da tradução, percebe-se, pela literatura sobre tradução escrita após a segunda metade do século XX, que se tornou um de seus tópicos centrais.

$\mathrm{O}$ interesse pelo tema da equivalência tradutória cresceu a partir de meados do século XX, no momento em que a tradução automática começava a florescer. Wilss $(1999$, p. 54) localiza o "boom" da automatização no período da Corrida Espacial. Na época, o programa espacial dos Estados Unidos foi superado pelo dos soviéticos com o lançamento do Sputnik, em 1957, uma derrota que, segundo Wilss, se deveu, sobretudo, ao fato de os estadunidenses não estarem a par da extensa produção bibliográfica, escrita em russo, sobre o novo satélite. Isso teria levado, então, a um desenvolvimento-relâmpago das técnicas de tradução automática nos Estados Unidos, entre 1950 e 1960.

De acordo com Werner Koller (2004), nesse mesmo período, a Linguística se consagrou como ciência, ao passo que os Estudos da Tradução ainda eram considerados apenas uma disciplina auxiliar, dedicada principalmente ao desenvolvimento da tradução automática. A tarefa dos Estudos da Tradução consistia em descre- 
ver correspondências e regularidades linguístico-tradutológicas, de modo a facilitar o trabalho dos sistemas de tradução automática (cf. KOLLER, 2004, p. 150). Isto é, estudar traduções era tão somente uma maneira de estabelecer correspondências formais, no nível do sistema linguístico (langue), entre as línguas.

É nesse contexto que, entre as décadas de 60 e 70, linguistas como Halliday et al. (1974), Marton (1968) e Krzeszowski (1971) buscam circunscrever o conceito de equivalência tradutória, a fim de fornecer as bases teóricas para a prática da análise contrastiva. Entretanto, cada teórico propõe a sua própria tipologia de equivalência, o que leva a uma grande fragmentação do conceito (cf. RODRIGUES, 2000, p. 19).

A tipologia de equivalência mais conhecida é, provavelmente, a de Eugene Nida, que, com a obra Towards a Science of Translating (1964), pretendia elevar a tradução ao status de ciência (cf. MUNDAY, 2008, p. 38). O autor parte do pressuposto de que nenhuma língua é inteiramente igual a outra e, por isso, não existe equivalência tradutória absoluta. Ainda assim, cabe ao tradutor buscar o equivalente mais próximo possível (cf. NIDA, 1964, p. 156 et seq.). Nesse modelo, o tradutor teria duas opções: priorizar a mensagem do texto de partida, conforme forma e conteúdo originais, ou tentar atingir um efeito equivalente ao do original, atendo-se à maior naturalidade possível na língua de chegada (cf. NIDA, 1964, p. 159). Essas são, respectivamente, as equivalências formal e dinâmica. Outras tipologias de equivalência são, por exemplo, as de Catford (1965) ${ }^{1}$, Kreszowski (1971), Newmark (1988) e Koller ([1979] 2004).

No entanto, não faltam críticas à equivalência. Isso se deve ao fato de esse conceito ser característico de uma concepção universalista de tradução, na medida em que pressupõe que, no ato da tradução, “[...] o significado sígnico [permaneça] intacto em outra

${ }^{1}$ Para uma análise detalhada das tipologias de Nida (1964) e Catford (1965), ver Rodrigues (2000, p. 37 et seq.). 
forma linguística" (KOPETZKI, 1996, p. 10) ${ }^{2}$. Rodrigues (2000) completa: "A 'equivalência' [...] associa-se a uma certa concepção de tradução, aquela que considera que a tradução deva reproduzir o texto de partida, ter o seu valor, pois seu uso remete à busca da unidade, da homogeneidade entre o texto traduzido e o texto original" (RODRIGUES, 2000, p. 28).

Como observado por Fujihara (2009), os teóricos desconstrutivistas, por exemplo, argumentaram que é impossível construir uma mesma significação em línguas diferentes, pois a tradução depende da interpretação e "[...] indivíduos diferentes partindo de backgrounds diferentes apreenderiam, ou melhor, construiriam, interpretações diferentes e, poderíamos dizer, complementares" (FUJIHARA, 2009, p. 274, grifo no original).

A vertente funcionalista da tradução, por sua vez, nega que possa existir uma equivalência tal como postulada pela vertente linguística porque o objetivo principal de qualquer tradução deve ser o escopo, ou seja, a função que o texto traduzido tem de desempenhar no contexto de chegada. Se esse escopo muda, altera-se também a tradução, não sendo, portanto, possível falar em equivalência entre texto de partida e texto de chegada (cf. FUJIHARA, loc. cit.).

Assim, com a superação da matriz linguística da tradução pelas vertentes posteriores, a noção de equivalência parece ter se tornado um estigma dos Estudos da Tradução de matriz linguística. Neste artigo, nosso objetivo é revisitar (para usar a expressão de Pym, 1997) esse conceito à luz da tipologia de equivalência de Koller (2004), apresentada em Einführung in die Übersetzungswissenschaft ("Introdução à Ciência da Tradução"). Sua obra foi escrita em alemão no final dos anos 70 e nunca chegou a ser traduzida para o inglês ou para o português, ficando assim praticamente restrita ao mundo germanófono, ao passo que Nida (1964) e Newmark (1988), por exemplo, escreveram suas obras originalmente em inglês e conquistaram assim maior visibilidade. Por esse motivo, dedicaremos a seção seguinte a uma síntese do modelo proposto por Koller.

${ }^{2}$ Traduções que não constem das referências bibliográficas são de minha autoria. 


\section{A equivalência em Koller (2004)}

Diante da confusão terminológica acerca da noção da equivalência, Koller faz uma distinção básica entre os termos Äquivalenz e Korrespondenz. Segundo o autor, a denominação "equivalência" deve ser empregada somente no que se refere aos Estudos da Tradução, enquanto a designação "correspondência" deve ficar restrita ao âmbito da Linguística Contrastiva (KOLLER, 2004, p. 217 et seq.). Koller justifica: a tarefa desta última é comparar sistematicamente duas ou mais línguas, com o objetivo de encontrar correspondências formais entre elas. O que está em jogo é a estrutura do idioma, a língua enquanto sistema (a langue de Saussure). Os Estudos da Tradução, por outro lado, "são a ciência da parole" (KOLLER, 2004, p. 223, grifo no original), na medida em que "[...] o tradutor produz [herstellen, no original] equivalência entre falas/textos da língua de partida e falas/textos da língua de chegada, não entre estruturas e orações de duas línguas." (KOLLER, 2004, p. 222).

Koller propõe ainda três máximas básicas para delimitar a sua compreensão do conceito de equivalência tradutória: 1) para que haja equivalência, deve haver uma relação tradutória (Übersetzungsbeziehung) entre dois textos; 2) o uso do termo equivalência pressupõe a definição de uma moldura de referência (Bezugsrahmen); 3) são considerados equivalentes quaisquer elementos linguísticos ou textuais que estabeleçam uma relação de equivalência entre língua de partida e língua de chegada (cf. KOLLER, 2004, p. 215).

Detenhamo-nos brevemente no conceito de moldura de referência. Para Koller, o original possui uma série de qualidades (de conteúdo, estéticas, funcionais etc.) que devem se refletir na tradução. Traduzir, porém, é um processo de tomada de decisões, o que significa que o tradutor, levando em conta as "condições linguísticas, estilísticas, textuais da parte dos receptores" (KOLLER, loc. cit.), muitas vezes terá de escolher quais qualidades do texto de partida devem ser recriadas no texto de chegada. Ao estabelecer essa 
"hierarquia de valores", ele define a sua moldura de referência. A depender do aspecto que o tradutor priorizar, resultará um tipo diferente de equivalência: 1) denotativa, 2) conotativa, 3) textual-normativa, 4) pragmática ou 5) estético-formal.

A primeira, equivalência denotativa, é produzida no nível lexical da linguagem. No modelo de Koller, essa categoria abarca cinco tipos de correspondência ${ }^{3}$ : um-para-um, um-para-muitos, muitos-para-um, um-para-zero e um-para-parte (a tradução da terminologia usada aqui é de autoria de Fujihara, 2010, p. 40).

A correspondência um-para-um pressupõe que dois termos em dois idiomas diferentes denotem exatamente a mesma coisa ( $\mathrm{Sa}$ mstag e "sábado", por exemplo), ainda que haja diferenças conotativas entre eles. No caso da correspondência um-para-muitos, a língua de chegada oferece, para uma única palavra na língua de partida, duas ou mais alternativas sinônimas (control $>$ Regelung, Steuerung, Bedienung etc). Na correspondência muitos-para-um, ao contrário, é a língua de partida que apresenta diversos lexemas alternativos (cf. KOLLER, 2004, p. 228 et seq.).

A correspondência um-para-zero, por sua vez, é central para o debate sobre a traduzibilidade das línguas. São as chamadas palavras "intraduzíveis". Nesse tipo de correspondência, há uma lacuna no sistema lexical da língua de chegada. A palavra alemã Berufsverbot, por exemplo, não tem um correspondente lexical em português. Cabe ao tradutor preencher essa lacuna, o que pode ser feito, segundo Koller, 1) por meio da utilização do estrangeirismo, 2) com uma tradução literal da palavra (Berufsverbot seria então "proibição do exercício profissional”), 3) pela utilização de um termo de significado próximo já consagrado na língua de chegada, 4) por meio de comentários, definições ou paráfrases, ou 5) através de um equivalente comunicativo, isto é, um conceito na língua de chegada

\footnotetext{
${ }^{3}$ Koller emprega aqui a palavra Entsprechung, que também pode ser traduzida como "correspondência", mas não significa o mesmo que Korrespondenz, um conceito vinculado pelo autor à Linguística Contrastiva, e não aos Estudos de Tradução. Entsprechung é entendida por ele como a relação de simetria denotativa entre dois elementos.
} 
que, pragmaticamente, exerce uma função semelhante ou comparável na língua de chegada (cf. KOLLER, 2004, p. 232 et seq.).

Vê-se, assim, que Koller rejeita a ideia da intraduzibilidade absoluta, pois, ainda que não haja equivalentes "perfeitos" entre duas línguas, há maneiras de contornar, ao menos parcialmente, as diferenças denotativas entre esses idiomas e culturas. $\mathrm{O}$ mesmo vale para o último tipo de correspondência, um-para-parte: uma palavra na língua de partida que possui um equivalente apenas parcial na língua de chegada. De acordo com Koller, as denominações de cores nas diversas línguas são um exemplo clássico de correspondência um-para-parte, "[...] porque o vermelho que figura, por exemplo, em uma escala de quatro partes, não corresponde ao vermelho segmentado por uma escala de sete partes." (KOLLER, 2004, p. 236). Para o autor, nomes de cores não são intraduzíveis, pois é possível verbalizá-los usando denominações mistas ("amareloesverdeado"), derivações ("azulado") e comparações ("verde musgo"), por exemplo.

Em seguida, Koller (2004, p. 240) apresenta a equivalência conotativa. Uma expressão possui, além de seu significado denotativo, diversas possibilidades de realização, ou seja, conotações. Exemplos de dimensões conotativas são a frequência de uso, o efeito que provocam ou o grupo ou lugar em que são utilizadas etc. (cf. KOLLER, 2004, p. 243 et seq.). A palavra Haupt, por exemplo, só é usada em um registro de linguagem mais elevado e, por isso, apresenta uma conotação inexistente no lexema "cabeça", ainda que os dois lexemas sejam, denotativamente, sinônimas.

Já a equivalência textual-normativa está atrelada às convenções específicas dos diferentes gêneros textuais. Em outras palavras: para que o leitor da tradução identifique determinado texto como pertencente ao gênero textual $\mathrm{A}$ ou $\mathrm{B}$, é necessário que o texto se atenha a determinadas normas estilísticas, que abrangem desde o vocabulário até a sintaxe e a própria estrutura do texto. A fim de produzir a equivalência textual-normativa, o tradutor deve respeitar as normas linguístico-estilísticas da língua de chegada, de modo a não ferir as convenções textuais dessa língua (cf. KOLLER, 2004, p. 247 et seq.). 
A equivalência pragmática, por sua vez, é orientada para o receptor, ou seja, o leitor da tradução. Para produzi-la, o tradutor deve assegurar a compreensão do texto pelo seu leitor, o que só pode ocorrer se o contexto comunicativo do texto de chegada for levado em conta. A equivalência pragmática exige que o tradutor seja capaz de mensurar o quão explicativo seu texto deve ser para que o leitor entenda as informações que lhe são apresentadas (cf. KOLLER, 2004, p. 249).

A quinta e última categoria de Koller é a equivalência estético-formal. Aqui, o tradutor deve recriar elementos artísticos do original, o que geralmente não é possível somente com os meios linguísticos disponíveis na língua de chegada. $\mathrm{Na}$ tradução literária, por exemplo, o objetivo do tradutor deve ser atingir um efeito estético análogo à expressividade individual do texto literário original (cf. KOLLER, 2004, p. 253), o que, não raro, significa que ele tem de reinventar por completo a qualidade estética do texto, cunhando também estruturas linguísticas inovadoras (cf. LIPINSKI, 1989, p. 218 apud KOLLER, 2004, p. 252).

\section{Linguagem e tradução para Koller: Relação contraditória?}

Apropriar-nos-emos, nesta seção, da estratégia de Rodrigues (2000), cuja “[...] análise está encaminhada a fim de argumentar que o conceito [de equivalência] se relaciona a determinadas concepções de tradução, de linguagem, de texto e de leitura" (RODRIGUES, 2000, p. 22). Discutiremos aqui a relação entre a concepção de linguagem adotada por Koller (2004) e a noção de tradução desenvolvida na mesma obra, no sentido de demonstrar que a concepção de linguagem do autor foge ao universalismo geralmente atribuído aos linguistas que teorizaram sobre a tradução. Nesse caso, cabe questionar se essa concepção de linguagem é coerente com a própria noção de equivalência, que, na teoria de tradução, é compreendida como um conceito essencialmente universalista, por pressupor a possibilidade de "transportar" 
conteúdos de uma língua A para uma língua $\mathrm{B}$, como vimos na primeira seção deste artigo.

De acordo com Kopetzki (1996, p. 9), a história da tradução foi marcada por dois modos de enxergar a diversidade das línguas e a sua importância para o pensamento humano: as posições universalista e a relativista. A primeira se caracteriza pela noção de que aquilo que é particular a uma determinada língua ou cultura é apenas um caso de aplicação (Anwendungsfall) de princípios gerais da linguagem humana, comuns a todas as línguas. A posição relativista, por sua vez, defende que a particularidade é o limite do geral, ou seja, que cada língua é uma representação da visão de mundo de uma comunidade linguística específica e todas elas diferem entre si.

Considerando-se que Koller criou uma tipologia de equivalência, poderíamos supor que o autor defenda uma concepção de linguagem de caráter universalista, pois, como vimos, a equivalência é considerada um conceito essencialmente universalista. Entretanto, como afirma Cruz (2000, p. 40), o modelo de Kopetzki “[...] não pode ser camisa-de-força ou fórmula de adivinhação". Isto é, não basta conhecer a concepção de linguagem de um teórico para, automaticamente, deduzir dela a sua concepção de tradução (e vice-versa).

Como é possível observar na síntese apresentada anteriormente, o modelo de Koller refuta a ideia de que, na língua de chegada, haja uma equivalência unívoca para cada palavra, oração ou texto na língua de partida. A premissa por trás de sua tipologia é o fato de que "[...] uma dada tradução pode enfatizar um dado aspecto (ou dados aspectos) em detrimento de outro(s)" (FUJIHARA. 2009, p. 274 et seq.), premissa esta que, por si só, já exclui a possibilidade de uma equivalência absoluta.

Observemos também um trecho da Einführung em que Koller (2004) comenta a relação entre língua e pensamento:

No processo de confrontação com o 'mundo' [...], nos apropriamos dos modos de ver desse 'mundo': paradigmas 
ou modelos da interpretação da realidade. Aprendemos a observar e a avaliar situações como casamento, sexualidade, morte, trabalho etc., de determinada(s) maneira(s). A língua tem uma participação importante no desenvolvimento e na fixação desses modos de ver (juntamente com a confrontação prática, não verbal, com a realidade): com a língua, nos comunicamos sobre a realidade e sobre as interpretações da realidade. Da mesma maneira que as interpretações da realidade são condicionadas culturalmente, ou seja, histórica e socialmente, os modos de falar sobre essas interpretações da realidade também são condicionados histórica e socialmente. As interpretações da realidade se refletem na língua e, ao mesmo tempo, são veiculadas pela língua. (KOLLER, 2004, p. 162, grifos no original).

Desta citação, destacamos o emprego da palavra "mundo" (Welt) entre aspas. Com isso, Koller relativiza a existência de um referente concreto, uma dimensão fisicamente apreensível à qual nos referimos na comunicação cotidiana. Em vez disso, prefere a expressão "interpretações da realidade" (Wirklichkeitsinterpretationen), representações mentais daquilo que apreendemos como "real", condicionadas pela dimensão histórico-social de uma cultura e, consequentemente, de uma língua. Se as interpretações subjetivas da realidade se refletem na língua ao falarmos sobre elas, a própria língua está necessariamente sujeita a condicionantes históricas e sociais. Por conseguinte, a língua para a qual se traduz não refletirá as mesmas interpretações da realidade da língua de partida, pois elas estão submetidas a condicionantes (às vezes radicalmente) diferentes.

Koller também retrata a relação língua-pensamento-cultura como um fenômeno dinâmico, pois falantes de qualquer língua são dotados de criatividade linguística. Para o autor, é verdade que nossa língua materna e as visões de mundo condicionadas por ela impõem limites à nossa compreensão, mas esses limites são refletidos, alterados e ampliados no processo de compreensão, e essas 
mudanças, por sua vez, voltam a se refletir no uso linguístico ${ }^{4}$ (cf. KOLLER, 2004, p. 186). Ao afirmar que as línguas condicionam o pensamento (e vice-versa), Koller rejeita precisamente a concepção de linguagem universalista, segundo a qual as línguas são apenas uma roupagem exterior para um significado único e estanque.

Por outro lado, ele define tradução como “[...] processo de transposição de um texto de uma língua (LP) para outra língua $(\mathrm{LC})^{5},[\ldots]$ sendo que o produto dessa transposição, a tradução, deve satisfazer determinadas exigências de equivalência" (KOLLER, 2004, p. 80). Vemo-nos aqui diante de uma contradição: apesar de aceitar que línguas diferentes pressupõem visões de mundo diferentes e que, por isso, não há um significado unívoco a ser buscado pelo tradutor, Koller nos apresenta uma concepção universalista de tradução, segundo a qual traduzir consiste em "transportar" conteúdos de uma língua para outra, deixando "o" significado intacto.

Koller, porém, atribui ao tradutor, enquanto indivíduo, a responsabilidade de estabelecer uma hierarquia de valores de equivalência (o que ele chama de "moldura de referência"), afinal esses valores variam para cada tradutor, na medida em que traduzir é interpretar e a interpretação é subjetiva (cf. KOLLER, 1988, p. 72, 78). Similarmente, o autor relativiza a noção de traduzibilidade: "Da mesma maneira que o entendimento de um texto nunca pode ser absoluto, mas sempre relativo e variável, a traduzibilidade de um texto também é sempre relativa” (KOLLER, 2004, p. 178).

Resta-nos ainda questionar como Koller se posiciona em relação ao próprio termo "equivalência". Ao comentar as definições de tradução de Catford (1965), Nida e Taber (1969), e Snell-Hornby

\footnotetext{
${ }^{4}$ A afirmação de Koller remete à posição relativista de Schleiermacher, que diz: "Uma pessoa não poderia pensar com total certeza nada o que estivesse fora dos limites dessa língua [materna]; [...] Mas, por outro lado, toda pessoa que pensa de uma maneira livre e intelectualmente independente também forma a língua à sua maneira" (SCHLEIERMACHER, 2001, p. 37).

${ }^{5}$ LP: língua de partida; LC: língua de chegada. Em alemão: Ausgangssprache (AS) e Zielsprache (ZS).
} 
e Vannerem (1986), Koller identifica um elemento comum a todas elas: o caráter normativo. Essa normatividade é expressa por meio do conceito de equivalência, termo que Koller prefere substituir por "exigência de equivalência" (Äquivalenzforderung), pois

As definições de tradução não são, de maneira alguma, puramente descritivas; elas sempre contêm um elemento normativo. Não é somente dito o que é o ato de traduzir, mas sempre, simultaneamente, o que este deve ser [...]." (KOLLER, 2004, p. 94, grifos no original).

Isto é, embora enfoquem diferentes aspectos do texto de partida (conteúdo, texto, normas, estilo etc.), os diversos modelos apregoam que essas características devem, necessariamente, permanecer inalteradas na passagem do texto original para o texto traduzido.

A partir da crítica feita por Koller, pode-se depreender que a sua tipologia não foi concebida a fim de impor aos tradutores como devem traduzir, ou seja, não exige que o tradutor encontre um equivalente dado de antemão, afinal "Os Estudos da Tradução não são uma ciência prescritiva” (KOLLER, 2004, p. 13). Com isso, Koller nega que a tarefa do tradutor seja encontrar, na língua de chegada, um equivalente unívoco e estanque para uma palavra ou oração da língua de partida. Pelo contrário, ele argumenta que é tarefa do tradutor, enquanto indivíduo, produzir essa equivalência ${ }^{6}$. A esse respeito, Pym (1997) ressalta que Koller, já na primeira edição de seu livro, datada de 1979, diversas vezes se refere:

\section{[...] à tradução como Herstellen ('produção' ou talvez 'fabricação') de um ou outro tipo de equivalência. Ches- terman (1991: 101-103) traduz esse Herstellen por 'obten-}

\footnotetext{
${ }^{6}$ Koller compartilha aqui da opinião de Ricœur, que diz que "[...] a equivalência [...] é mais propriamente produzida pela tradução do que presumida por ela" (RICEEUR, 2011, p. 66, grifo no original).
} 
ção', o que remeteria à tentativa do tradutor de alcançar um objetivo pré-estabelecido, tornando Koller, em última instância, um teórico daquilo que Mossop (1983), com razão, criticou como "a busca da equivalência", o tipo de atividade que condena o tradutor a sempre olhar para trás. Porém, uma teoria que localiza a equivalência no nível da parole, uma teoria que inclui normas e leitores da língua-alvo entre os seus parâmetros, seria lida mais justamente como um conto de como tradutores efetivamente produzem essa especificidade chamada equivalência (PYM, 1997, p. 4, grifos no original).

\section{Conclusão}

A obra de Koller foi publicada em um momento no qual não parecia ser possível conceber a tradução sem evocar uma noção universalista de equivalência. Isso mudou à medida que a teoria de tradução se desenvolveu e outras vertentes (o funcionalismo, a teoria dos polissistemas, a desconstrução etc.) surgiram e incorporaram diversas condicionantes ao ato tradutório (culturas de partida e de chegada, o propósito da tradução e a subjetividade do próprio tradutor, por exemplo), tornando a equivalência um conceito obsoleto nos Estudos da Tradução.

Embora seja necessário problematizar a definição universalista de tradução adotada por Koller (2004, p. 80), que, como vimos, vai de encontro à sua concepção relativista de linguagem, propomos aqui alguns questionamentos: ao teorizar sobre a tradução, é realmente possível prescindir inteiramente da noção de equivalência, entendida aqui como a relação entre o texto de partida e o texto de chegada, estabelecida pelo tradutor enquanto indivíduo, a partir de sua interpretação subjetiva do texto original? Como o próprio Koller afirma, a "verdadeira tradução" (eigentliche Übersetzung), objeto de estudo dos Estudos da Tradução, se caracteriza por "seu vínculo absolutamente específico com um texto de partida” (KOL- 
LER, 2004, p. 88). Se perdermos de vista esse vínculo, ainda é possível falar em tradução?

Por fim, embora não se possa afirmar que Koller nos apresenta uma visão inteiramente relativista de tradução, tampouco que a noção de equivalência em si possa ser considerada relativista, este breve exame da obra do autor ilustrou que ele muitas vezes relativiza o conceito tradicional de equivalência. Parece-nos, portanto, ser de grande valia revisitar a noção de equivalência e não descartar a contribuição de pesquisadores como Koller somente com base no pressuposto de que a matriz linguística da tradução está superada. Esperamos ter demonstrado que, ao ler obras de autores dessa vertente "com algum grau de caridade" (PYM, 1997, p. 5), como procuramos fazer neste artigo, é possível identificar nelas traços surpreendentes e passíveis de uma análise mais minuciosa, mesmo nos dias de hoje, quando a equivalência já parece uma ideia ultrapassada.

\section{Referências}

CATFORD, J. C.. A linguistic theory of translation: an essay in applied linguistics. Oxford: Oxford University Press, 1965.

CRUZ, C. D. . A querela de universalistas e relativistas. In: O trabalho do tradutor: em busca de uma teoria para a prática. São Paulo: FFLCH/USP, 2012, p. 37-52. Originalmente apresentada como tese de doutorado, Universidade de São Paulo. Disponível em: <http://www.teses.usp.br/teses/disponiveis/8/8144/ tde-14012013-140329/pt-br.php >. Acesso em: 23 abr. 2017.

FUJIHARA, A. K.. Tipos e graus de equivalência em Koller. In: Equivalência Tradutória e Significação. Curitiba: Universidade Federal do Paraná. 2010, p. 38-44. Originalmente apresentada como dissertação de mestrado, Universidade Federal do Paraná. Disponível em: < http://dspace.c3sl.ufpr.br/ 
dspace/bitstream/handle/1884/25348/FUJIHARA;jsessionid=F5B44E843C983B 4320F419739927EE94? sequence $=1>$. Acesso em: 23 abr. 2017.

FUJIHARA, A. K.. Equivalência tradutória e significação. Estudos Linguísticos. São Paulo, n. 38, abr. 2009, p. 273-283. Disponível em: < http://www.gel.org.br/ estudoslinguisticos/volumes/38/EL_V38N1_22.pdf >. Acesso em: 21 abr. 2017.

HALLIDAY, M. et al.. Comparação e tradução. In: . As ciências linguísticas e o ensino de línguas. Trad. Myriam Freire Morau. Petrópolis: Vozes, 1974, p. 136-161.

KOLLER, W.. Einführung in die Übersetzungswissenschaft. 7. ed. Wiebelsheim: Quelle \& Meyer, 2004.

KOPETZKI, A.. Einheit oder Vielfalt. Universalistische und relativistische Positionen in der Sprachtheorie. In: . Beim Wort nehmen. Sprachtheoretische und ästhetische Probleme der literarischen Übersetzung. Stuttgart: M\&P, 1996, p. 19-43.

KRZESZOWSKI, T.. Equivalence, congruence and deep structure. In: NICKEL, G. (Org.). Papers in contrastive linguistics. Cambridge: Cambridge University Press, 1971, p. 37-48.

LIPINSKI, K.. Über die Sonderstellung der literarischen Übersetzung. In: KATNY, Andrzej (Org.). Studien zur kontrastiven Linguistik und literarischen Übersetzungen. Frankfurt/Main: Peter Lang, 1989, p. 211-220.

MARTON, W.. Equivalence and congruence in transformational contrastive studies. Studia Anglica Posnaniensia, [Poznań], v.1, 1968, p. 53-62.

MUNDAY, J.. Equivalence and equivalent effect. In: MUNDAY, Jeremy. Introducing Translation Studies. Theories and applications. 2. ed. Londres, Nova Iorque: Routledge, 2008, p. 36-54.

NEWMARK, P.. A Textbook of Translation. Nova Iorque, Londres: Prentice Hall, 1988. 
NIDA, E. A.. Toward a Science of Translating. Leiden: E. J. Brill, 1964.

NIDA, E. A.; TABER, C. R.. The theory and practice of translation. Leiden: E.J. Brill, 1969.

PYM, A.. Koller's Äquivalenz revisited. The Translator. [S.1.], v. 3, n. 1, 1997, p. 71-79. Disponível em: < http://usuaris.tinet.cat/apym/on-line/reviews/1997_ koller.pdf $>$. Acesso em: 21 abr. 2017.

RICEUUR, P.. Uma Passagem: Traduzir o intraduzível. In: . Sobre a tradução. Trad. Patrícia Lavelle. Belo Horizonte: UFMG, 2011, p. 59-71.

RODRIGUES, C.. Tradução e diferença. São Paulo: Ed. UNESP, 2000.

SCHLEIERMACHER, F.. Sobre os diferentes métodos de tradução. Trad. Margarete von Mühlen Poll. In: Heidermann, Werner (Org.). Clássicos da teoria da tradução (Antologia bilíngue, alemão-português, v. 1). Florianópolis: UFSC, 2001, p. 26-85.

SNELL-HORNBY, M.; VANNEREM, M.. Die Szene hinter dem Text: scenes-and-frame-semantics in der Übersetzung. In: SNELL-HORNBY, M.. Übersetzungswissenschaft - eine Neuorientierung. Zur Integrierung von Theorie und Praxis. Tübingen: Uni-Taschenbücher, 1986, p. 184-205.

WILSS, W.. Übersetzen und Dolmetschen im 20. Jahrhundert. 1. Ed. Saarbrücken: ASKO Europa Stiftung, 1999.

Recebido em: 24/04/2018

Aceito em: 05/07/2018

Publicado em setembro de 2018

Carolina Ribeiro Minchin. E-mail: Ca_Minchin92@hotmail.com

ORCID: https://orcid.org/0000-0002--9146-1392 